on data contained in the Survey on Household Budgets (POF 2002-2003).

Materials and Methods This analysis is conducted with the data from POF 2002-2003 which involved interviews on a sample of 48470 families.

Results The sum of all drug costs for diabetes treatment equals US\$ 249 million. Among those who have acquired any drugs for diabetes care the average expense was US\$ 6.30. 31.1\% of the drugs for diabetes were obtained through the NHS and $64.2 \%$ were bought in a drugstore or pharmacy. Those with family incomes of up to US\$ 137.00 spend the equivalent of $4.28 \%$ the income on medicines for diabetes. While those with family incomes above US\$2000.00 have a drug spending for diabetes equivalent to $0.51 \%$ of their income.

Conclusion Brazil spends the equivalent of $0.02 \%$ of its GDP on medicines for the treatment of diabetes. The average monthly spend on medicines for diabetes is US\$ 6.30. Despite the health system in Brazil claim to be universal, only $31 \%$ of medications for diabetes were covered by the system.

\section{P2-177 ACCUMULATION OF OBESITY-RELATED EATING BEHAVIOURS AND THE INCIDENCE OF TYPE 2 DIABETES AMONG MIDDLE-AGED JAPANESE MEN AND WOMEN: THE CIRCULATORY RISK IN COMMUNITIES STUDY (CIRCS)}

doi:10.1136/jech.2011.142976j.12

\begin{abstract}
${ }^{1,2} \mathrm{~K}$ Maruyama, ${ }^{* 2} \mathrm{M}$ Kiyama, ${ }^{2,3} \mathrm{~S}$ Sato, ${ }^{1,2} \mathrm{~T}$ Ohira, ${ }^{2} \mathrm{~K}$ Maeda, ${ }^{1,2} \mathrm{H}$ Noda, ${ }^{2} \mathrm{~S}$ Nishimura, ${ }^{2} \mathrm{~A}$ Kitamura, ${ }^{2} \mathrm{~T}$ Okada, ${ }^{1,2} \mathrm{H}$ Imano, ${ }^{2} \mathrm{M}$ Nakamura, ${ }^{2} \mathrm{Y}$ Ishikawa, ${ }^{4} \mathrm{M}$ Kurokawa, ${ }^{5} \mathrm{~K}$ Yamagishi, ${ }^{1} \mathrm{H}$ Iso. ${ }^{1}$ Osaka University Graduate School of Medicine, Osaka, Japan; ${ }^{2}$ Osaka Medical Center for Health Science and Promotion, Osaka, Japan; ${ }^{3}$ Chiba Prefectural Institute of Public Health, Chiba, Japan; ${ }^{4}$ Osaka Prefecture University School of comprehensive rehabilitation, Osaka, Japan; ${ }^{5}$ University of Tsukuba Graduate School of Comprehensive Human Sciences, and Institute of Community Medicine, Tsukuba, Japan
\end{abstract}

Introduction To examine whether the accumulation of obesityrelated eating behaviours such as eating quickly, eating until full, eating right before bedtime and breakfast skipping are associated with incidence of type 2 diabetes mellitus (T2DM) among middleaged Japanese men and women.

Methods The 2840 subjects ( 890 men and 1950 women) who were aged 40-69 year and free of T2DM were enrolled at baseline survey from 2003 to 2006 in a community-based longitudinal study, the CIRCS. The subjects were asked following four eating behaviours by questionnaire at baseline: "speed of eating", "eating until full", "eating right before bedtime" and "breakfast skipping". T2DM was defined as fasting serum glucose $\geq 7.0 \mathrm{mmol} / \mathrm{l}$, non-fasting serum glucose $\geq 11.1 \mathrm{mmol} / 1$ or medication for T2DM. We followed up to March 2010, and calculated HR and 95\% coefficient interval (95\% CI) of T2DM by using Cox proportional hazard model after adjustment for potential risk factors.

Results During 7-year follow-up period, 155 cases (70 men and 85 women) had an onset of T2DM. We calculated multivariate HR (95\% CI) of T2DM for each number of eating behaviours among both men and women. Compared with persons without any eating behaviours, the multivariable HR (95\% CI) of persons with 1, 2 and $\geq 3$ of eating behaviours were 2.35 (1.06 to 5.19), 1.54 (0.65 to 3.63) and 3.24 (1.29 to 8.13), p for trend $=0.09$ in men and 0.92 (0.52 to 1.62), 0.67 (0.35 to 1.30 ) and 1.97 (0.92 to 4.22 ), $\mathrm{p}$ for trend $=0.67$ in women.

Conclusion Our finding suggests that the accumulation of obesityrelated eating behaviours raise the risk of T2DM for middle-aged Japanese men.

\section{P2-178 THE ASSOCIATIONS OF DIETARY FOLATE, VITAMIN $B_{6}$ AND $B_{12}$ INTAKES WITH RISK OF SUDDEN CARDIAC DEATH: THE CIRCULATORY RISK IN COMMUNITIES STUDY (CIRCS)}

doi:10.1136/jech.2011.142976j.13

${ }^{1,2} \mathrm{M}$ Maruyama, ${ }^{*}{ }^{1,2} \mathrm{~T}$ Ohira, ${ }^{1,2} \mathrm{H}$ Imano, ${ }^{2} \mathrm{~A}$ kitamura, ${ }^{2} \mathrm{M}$ Kiyama, ${ }^{2} \mathrm{~T}$ Okada, ${ }^{2} \mathrm{~K}$ Maeda, ${ }^{3} \mathrm{~K}$ Yamagishi, ${ }^{2,4} \mathrm{H}$ Noda, ${ }^{2} \mathrm{Y}$ Ishikawa, ${ }^{2} \mathrm{~T}$ Shimamoto, ${ }^{1} \mathrm{H}$ Iso. ${ }^{1}$ Department of Social and Environmental Medicine, Osaka University, Suita, Japan; ${ }^{2}$ Osaka Medical Center for Health Science and Promotion, Osaka, Japan; ${ }^{3}$ Department of Public Health Medicine, University of Tsukuba, Tsukuba, Japan; ${ }^{4}$ Department of Health Care Economics and Industrial Policy, Suita, Japan

Introduction To examine whether dietary folate, vitamin $\mathrm{B}_{6}$ and $\mathrm{B}_{12}$ intakes are associated with the risk of sudden cardiac death (SCD) among Japanese men and women.

Method We conducted a nested case-control study. For each case of SCD entered between 1973 and 2001 in the CIRCS, two controls were randomly selected for each case and matched for age ( \pm 3 years), sex and community from among participants without history of SCD. The 77 cases and 154 controls aged 30-84 years were enrolled. Dietary folate, vitamin $\mathrm{B}_{6}$ and $\mathrm{B}_{12}$ intakes were assessed by 1 day $24 \mathrm{~h}$ dietary recall. We calculated conditional OR and $95 \% \mathrm{CI}$ of each nutrients for risk of SCD adjusted for potential confounding factors.

Result Higher intake of folate was associated with lower risk of SCD. The multivariable adjusted OR $(95 \% \mathrm{CI})$ of highest quartile was 0.32 (95\% CI 0.12 to 0.82$)$, p for trend $=0.06$ compared with lowest quartile. However, vitamin $\mathrm{B}_{6}$ and $\mathrm{B}_{12}$ intakes were not associated with risk of SCD. The multivariable adjusted OR $(95 \%$ $\mathrm{CI})$ of highest quartile of vitamin $\mathrm{B}_{6}$ and $\mathrm{B}_{12}$ intakes were $1.25(95 \%$ CI 0.49 to 3.21 ), $p$ for trend $=0.64$ and 0.83 (95\% CI 0.34 to 1.98$), p$ for trend $=0.86$ compared with lowest quartiles, respectively.

Conclusion Our findings suggest that higher dietary folate intake is associated with lower risk of SCD among Japanese men and women

\section{P2-179 A META-ANALYSIS OF THE RELATIONSHIP BETWEEN AGE AT PUBERTY AND TESTICULAR CANCER}

doi:10.1136/jech.2011.142976j.14

${ }^{1} \mathrm{M}$ Maule, ${ }^{* 1,2} \mathrm{~J}$ A L Malavassi, ${ }^{1} \mathrm{~L}$ Richiardi. ${ }^{1}$ Cancer Epidemiology Unit, University of Turin, Torino, Italy; ${ }^{2}$ CR-Fundacion, Universidad Autonoma de Centro America, San José, Costa Rica

Introduction Testicular cancer is one of the most rapidly increasing tumour types but its aetiology is still largely unexplained. Cryptorchidism and familial testicular cancer, the most established risk factors, may explain $<10 \%$ of all cases. Among investigated postnatal factors, early puberty was suggested as a potential risk factor but the topic has been poorly investigated.

Methods We undertook a meta-analysis of the association between age at puberty and testicular cancer risk. Search strategies were conducted in PubMed on December 2010. All markers of puberty onset (age at voice change, age at first nocturnal emission, age when started shaving, and reported age at onset) were considered. We recategorised age at puberty from all the studies into a common threelevel variable (younger age than peers, same age as peers, older age then peers), while analyses using quantitative information are ongoing.

Results A total of 348 references were retrieved, of which 11 met the inclusion criteria. Later puberty appeared to be protective. In particular later vs same age at reported onset of puberty gave an $\mathrm{OR}$ of 0.65 (95\% CI 0.52 to 0.78 ) based on three studies, later vs same age at voice change an OR of 0.79 (95\% CI 0.68 to 0.92 ) based on five studies, and later vs same age at start shaving an OR of 0.84 (95\% CI 0.75 to 0.95 ) based on five studies. Early puberty showed a smaller or no protective effect. 